\title{
Research on Crude Oil Demulsification Using the Combined Method of Ultrasound and Chemical Demulsifier
}

\author{
Mingxu Yi, Jun Huang, and Lifeng Wang \\ School of Aeronautic Science and Engineering, Beihang University, Beijing 100191, China \\ Correspondence should be addressed to Lifeng Wang; wanglf1972@163.com
}

Received 1 November 2016; Revised 28 December 2016; Accepted 8 February 2017; Published 26 March 2017

Academic Editor: Davide Vione

Copyright (C) 2017 Mingxu Yi et al. This is an open access article distributed under the Creative Commons Attribution License, which permits unrestricted use, distribution, and reproduction in any medium, provided the original work is properly cited.

In this paper, experiments of crude oil demulsification using ultrasound, chemical demulsifier, and the combined method of ultrasound and chemical demulsifier, respectively, at different temperatures $\left(40^{\circ} \mathrm{C}, 60^{\circ} \mathrm{C}\right.$, and $\left.70^{\circ} \mathrm{C}\right)$ are carried out. The photos of water droplet distribution in crude oil, taken with microscopic imaging system, before and after demulsification using the above methods at $70^{\circ} \mathrm{C}$ are given. Research results show that the combined method of ultrasound and chemical demulsifier has the best demulsification effect, followed by chemical demulsifier. Ultrasound without using chemical demulsifier has the least demulsification effect. Furthermore, the impact of ultrasonic power, treatment time, and temperature on crude oil demulsification using the combined method of ultrasound and chemical demulsifier is studied. Results indicate that the final dehydration rate increases with the increase of temperatures and ultrasonic power and almost does not change with the increase of ultrasonic treatment time. These important conclusions will provide the foundation for an extensive application of the combined method of ultrasound and chemical demulsifier.

\section{Introduction}

The formation of water-in-oil emulsions during crude oil production is a problem for crude oil industry. Until now, the most common way of separating water from crude oil is by using chemical demulsifiers [1]. Although chemical demulsifiers are widely used in crude oil industry, they are not very efficient [2].

Until recently, ultrasonic irradiation was considered as an efficient method to desalt heavy crude oil [3]. As an easier, simpler, and more efficient method, ultrasonic technology has recently been applied to water-oil emulsion separation on the laboratory scale in many literature papers [3-11]. Experimental results in these papers suggest that the separation is enhanced under ultrasonic irradiation. And then, many kinds of ultrasonic dehydration apparatus [12-15] on the large scale have been designed successfully, which enabled the scale-up of ultrasound-assisted dehydration. This method was first used in refinery oil dehydration by Yu et al. [16] to remove water in crude oil emulsion, which is mostly made by deliberate injection of water into the crude oil in order to dissolve soluble salts especially $\mathrm{NaCl}$ [3]. Their experimental study on the influence of sound field parameters on the water in crude oil emulsion behavior indicated that the response efficiency of the ultrasonically irradiated dispersed water phase to drive, coalesce, and segregate was similar to the behavior of suspended particles [17], droplets [18], and bubbles $[19,20]$ in sound field.

Ultrasonic demulsification technique mainly uses the agglomeration effect and the viscosity reducing effect of ultrasonic wave on crude oil to make water droplets in the crude oil gather and accelerate oil and water two-phase separation [21, 22]. References [2, 23] prove that lower ultrasonic frequency is good for ultrasonic demulsification when power of transducer remained unchanged.

Higher efficiency of demulsification could be achieved by combining demulsifier and electrostatic treatment [24]. However, in order to achieve suitable demulsification efficiency, desalted water (in case of desalting water) and more demulsifiers must be added. Other methods, such as the combination of demulsifier and hydrocyclones [25] and the combination of demulsifier and ultrasonic radiation $[4,10,23,26]$, have been evaluated, but these techniques are still not used in industrial crude oil demulsification processes 
[2]. In a word, the influence of parameters of transducer (frequency, power, and treatment time) on the effect of crude oil demulsification is investigated in these references, and the effect of the primary factors on crude oil demulsification using chemical demulsifier is also studied. Results show that the rate of droplet coalescence at higher ultrasonic frequency is significantly lower than that at lower ultrasonic frequency at earlier time when the droplets are small; bigger values of ultrasonic power are not always better, as they should be controlled in an optimal range; bigger values of ultrasonic treatment time are not always better.

However, the systematic comparison of crude oil demulsification using ultrasonic treatment, chemical agent alone, and the combination of ultrasonic and chemical demulsification methods, respectively, was not fully investigated.

In this paper, experiments of crude oil demulsification using ultrasound, natural sedimentation, chemical demulsifier, and the combined method of ultrasound and chemical demulsifier, respectively, at different temperatures are investigated. It is shown here that higher efficiency of crude oil demulsification can be achieved by the combined method of ultrasound and chemical demulsifier. The purpose of this paper is to provide the foundation for an extensive application of the combined method of ultrasound and chemical demulsifier.

\section{Experimental Apparatus, Materials, and Procedures}

Experiments of demulsification of produced liquid containing heavy oil by sonochemical treatment were carried out by Zhang in 2008 in China University of Petroleum (East China) [27]. On the basis of these experiments, the comparison of crude oil demulsification using ultrasonic wave, chemical demulsifier, and the combined method of ultrasound and chemical demulsifier is further investigated in this section.

2.1. Experimental Apparatus and Materials. The main experimental apparatuses are explosion-proof pneumatic mixer, stopwatch, HH-8 digital resistance heating furnace, densitometer, constant temperature waters, and WL-8XZ temperature controller. Explosion-proof pneumatic mixer, HH-8 digital resistance heating furnace, and WL-8XZ temperature controller are shown in Figures 1, 2, and 3, respectively. Three NC-M type transducers, produced in Wuxinni Ultrasonic Equipment Co., Ltd., are used to study crude oil demulsification using the combined method of ultrasound and chemical demulsifier. Transducers and their parameters are shown in Figure 4 and Table 1, respectively.

Explosion-proof pneumatic mixer is produced by DEBAO pneumatic company in Zhejiang Province in China. The advantages of this mixer are stepless speed regulation, elevated torque, explosion-proof, operating intelligence, automation, and suitability for factory operations. HH-8 digital resistance heating furnace is produced by Zheng Kai Precision Instrument Co., Ltd., in the city of Dongguan in China. Its power is $1000 \mathrm{~W}$, the temperature control range is room temperature $\sim 100^{\circ} \mathrm{C}$, and advantages are accurate

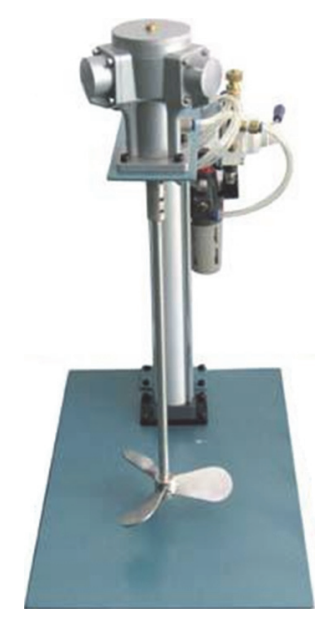

FIGURE 1: Explosion-proof pneumatic mixer.

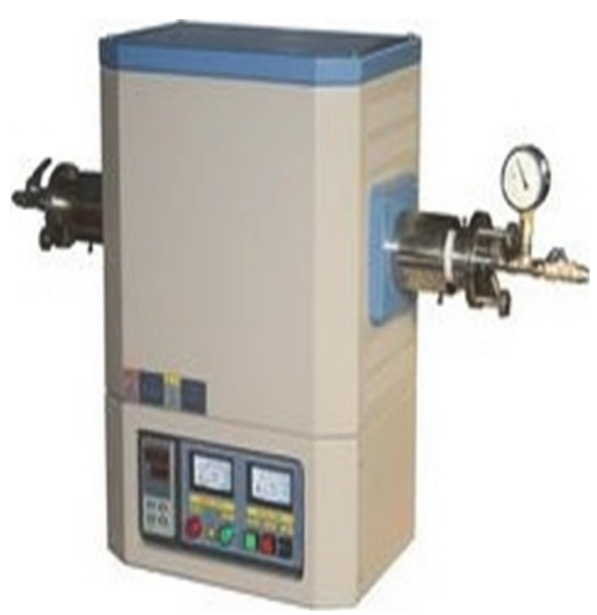

FIGURE 2: HH-8 digital resistance heating furnace.

temperature control, digital display, and automatic temperature control. WL-8XZ temperature controller is produced by Tai Xi Electronics, Ltd., in the city of Guangzhou in China. Setting temperature is $-30^{\circ} \mathrm{C} \sim 120^{\circ} \mathrm{C}$. Digital temperature showing in real time can be achieved using this temperature controller.

In order to make the experimental results more representative of reality, watery crude oils from Daqing Oilfield (the freezing point is $67.2^{\circ} \mathrm{C}$ ) were selected as the samples to study the effects of crude oil demulsification using ultrasound, chemical demulsifier, and the combined method of ultrasound and chemical demulsifier, respectively.

The initial water content, density, viscosity, and salt content of crude oil are $25.23 \%, 0.9247 \mathrm{~g} \cdot \mathrm{cm}^{-3}, 145000 \mathrm{mP} \cdot \mathrm{s}$, and $95367 \mathrm{mg} / \mathrm{L}$, respectively. The concentration of Type SP demulsifier is $250 \mathrm{mg} / \mathrm{L}$. The container of crude oil was a mixing cylinder with stopper, with the following features: total volume $100 \mathrm{ml}$, outside diameter $30 \mathrm{~mm}$, and height $260 \mathrm{~mm}$. The amount of crude oil sample was $70 \mathrm{ml}$. After stirring crude oil well using pneumatic mixer, the experiment of ultrasonic demulsification was carried out immediately. 


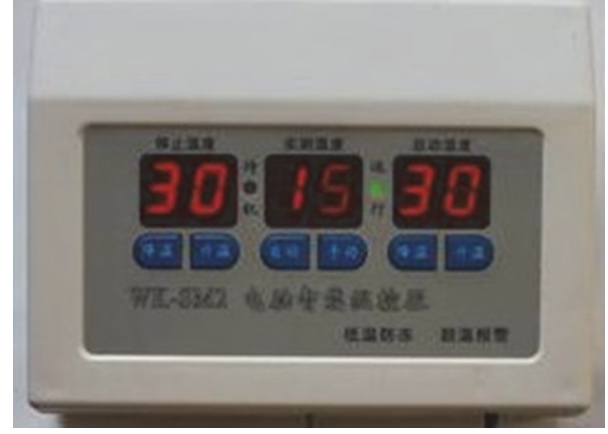

FIGURE 3: WL-8XZ temperature controller.

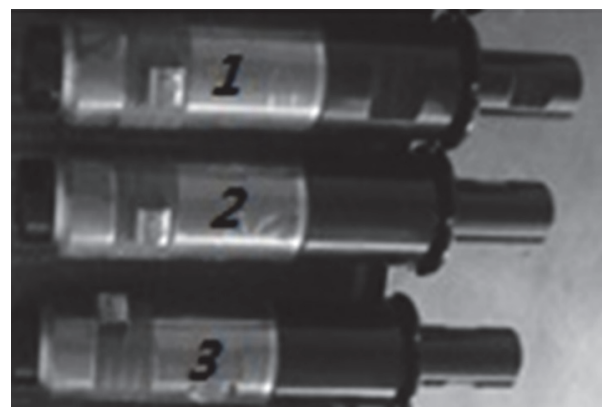

FIGURE 4: NC-M ultrasound transducer.

TABle 1: Parameters of ultrasonic transducers.

\begin{tabular}{lcc}
\hline Transducer number & $\begin{array}{c}\text { Transducer frequency } \\
(\mathrm{kHz})\end{array}$ & $\begin{array}{c}\text { Transducer rated } \\
\text { power }(\mathrm{W})\end{array}$ \\
\hline 1 & 20 & 150 \\
2 & 30 & 100 \\
3 & 40 & 50 \\
\hline
\end{tabular}

\subsection{Experimental Procedures}

(1) We heated the constant temperature water to the required temperature.

(2) We added the SP demulsifier to the prepared watery crude oil and stirred the mixture of crude oil and demulsifier using high speed mixer.

(3) We processed the mixed sample using ultrasonic transducer.

(4) When the dewatering amount did not appear to add up, we recorded the total volumes of the dehydrated water and the whole mixed sample.

\section{Experimental Results and Discussion}

3.1. The Comparison of Crude Oil Demulsification Using Ultrasound, Natural Sedimentation, Chemical Demulsifier, and the Combined Method of Ultrasound and Chemical Demulsifier. Under the same ultrasonic power $(150 \mathrm{~W})$ and ultrasonic frequency $(20 \mathrm{kHz})$, experiments of crude oil demulsification using ultrasound, natural sedimentation, chemical demulsifier, and the combined method of ultrasound and chemical

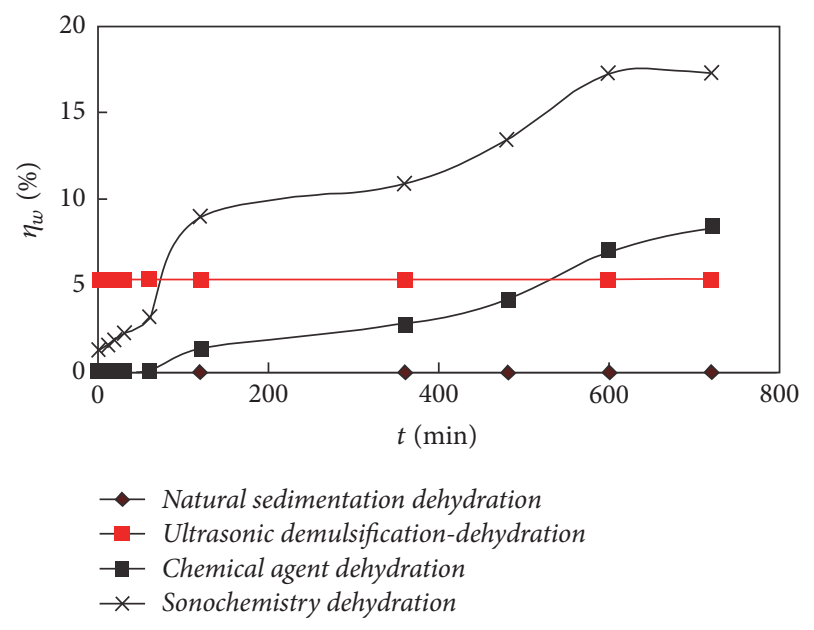

FIgURE 5: The comparison of demulsifying and dehydrating crude oil using ultrasonic excitation, natural sedimentation, chemical demulsifier, and sonochemistry method, respectively, at $40^{\circ} \mathrm{C}$.

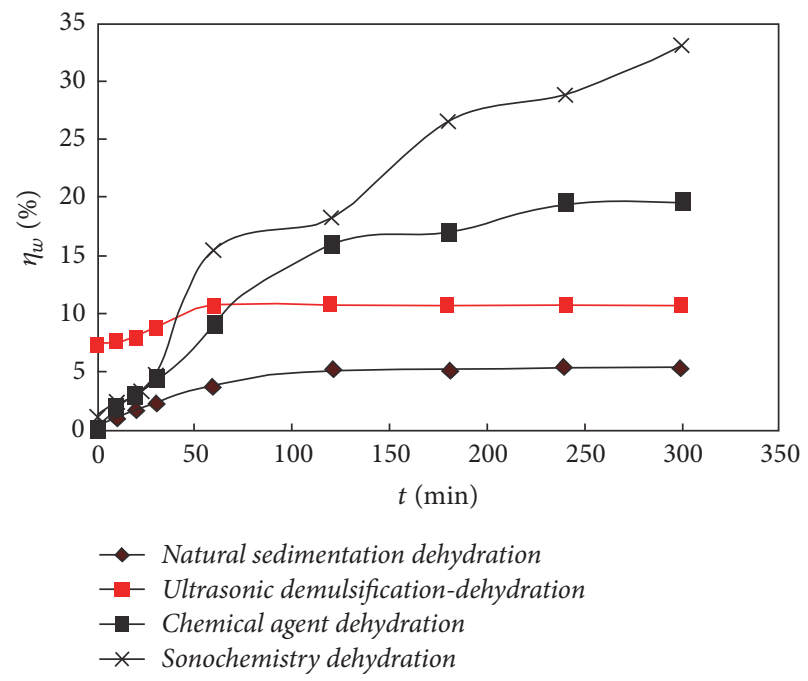

FIGURE 6: The comparison of demulsifying and dehydrating crude oil using ultrasonic excitation, natural sedimentation, chemical demulsifier, and sonochemistry method, respectively, at $60^{\circ} \mathrm{C}$.

demulsifier, respectively, at different temperatures $\left(40^{\circ} \mathrm{C}\right.$, $60^{\circ} \mathrm{C}$, and $70^{\circ} \mathrm{C}$ ) were carried out. Results are shown in Figures 5, 6, and 7 respectively.

As can be seen in Figure 5, ultrasound can dehydrate crude oil instantaneously, but the dehydration rate is nearly invariable and natural sedimentation has the lowest final dehydration rate; as time goes on, the combined method of ultrasound and chemical demulsifier has the best demulsification effect compared to that of using ultrasound and chemical demulsifier separately at $40^{\circ} \mathrm{C}$.

As can be seen in Figure 6, the combined method of ultrasonic irradiation and chemical demulsifier has the best demulsification effect, followed by chemical demulsifier, and ultrasound without using chemical demulsifiers has the least demulsification effect at $60^{\circ} \mathrm{C}$. 


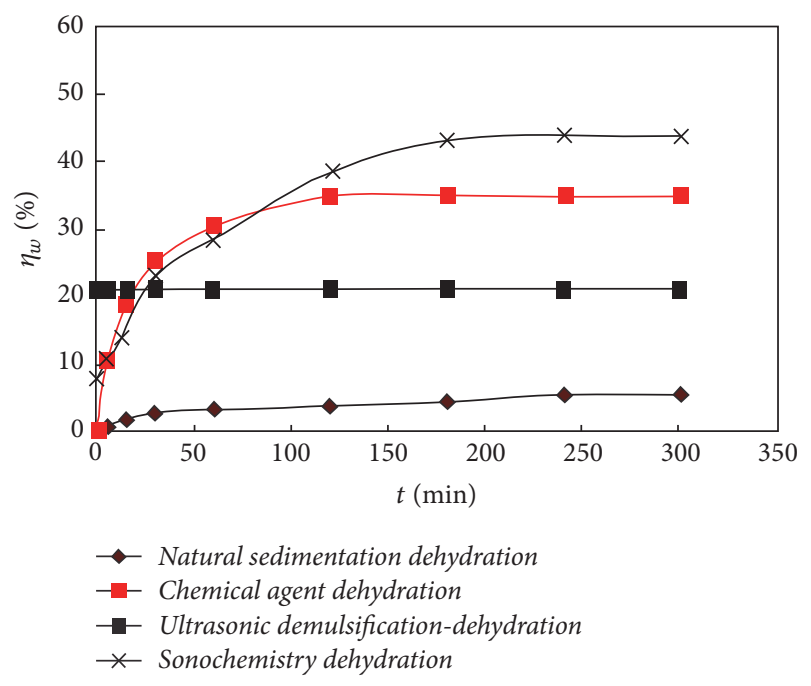

FIGURE 7: The comparison of demulsifying and dehydrating crude oil using ultrasonic excitation, natural sedimentation, demulsifier chemical, and sonochemistry method, respectively, at $70^{\circ} \mathrm{C}$.

It can be seen from Figure 7 that the dehydration rate using the combined method of ultrasound and chemical demulsifier is double than that using ultrasonic treatment, and it is nearly higher compared to the use of chemical demulsifier at $70^{\circ} \mathrm{C}$ over time. The above three figures allow for a similar conclusion: the combined method of ultrasound and chemical demulsifier has the best demulsification effect, followed by chemical demulsifier and ultrasound without using chemical demulsifiers. Furthermore, they also indicate that the final dehydration rates when using the above four demulsification methods all increase as the temperatures rise, which indicates that temperature is an important factor that affects the demulsification effect.

The photos of water droplet distribution in crude oil using the above demulsification methods are taken with microscopic imaging system at $70^{\circ} \mathrm{C}$. Figure $8(\mathrm{a})$ is the water droplet distribution in crude oil before demulsification, Figure $8(\mathrm{~b})$ is the water droplet distribution in crude oil using chemical demulsifier, Figure $8(\mathrm{c})$ is the water droplet distribution in crude oil using ultrasonic excitation without using chemical demulsifiers, and Figure $8(\mathrm{~d})$ is the water droplet distribution in crude oil using the combined method of ultrasound and chemical demulsifier.

It can be seen from Figure 8(a) that there are many water droplets with different diameters in crude oil before demulsification. From Figure 8(b), the number and diameters of water droplets in crude oil have all been reduced with the chemical demulsifier. From Figure 8(c), the number of water droplets and their diameters have been somewhat reduced after ultrasonic excitation. However, the diameters of water droplets are bigger than that in Figure 8(b). Moreover, the number of water droplets with big diameter is still higher in Figure 8(c) than in Figure 8(b), which indicates that the demulsification effect using chemical demulsifier is better than that using ultrasound. It can be seen from Figure 8(d) that the number of water droplets has been greatly reduced and the water droplets with big diameter has become fewer compared with Figures 8(b) and 8(c) after demulsification using the combined method of ultrasound and chemical demulsifier. It can be seen in Figure 8(a) that there are many big and smaller water drops before sonochemistry treatment. The water content is $48.5 \%$. It can be seen in Figure 8(d) that the number of big water droplets in crude oil has all been greatly reduced after sonochemistry treatment. The water content was $18.5 \%$ after sonochemistry treatment. Briefly, by comparing Figures 8(a), 8(b), 8(c), and 8(d), the combined method of ultrasound and chemical demulsifier has the best demulsification effect, followed by chemical demulsifier and ultrasonic irradiation without using chemical demulsifiers; besides, it is proved once again from the above four figures that the smaller the drops, the more difficult the demulsification.

Natural sedimentation dehydration is a time-consuming process and has no good dehydration effect. That is why the other three dehydrating methods are significantly better than natural sedimentation dehydration. Extraheavy crude oil demulsification using ultrasound is achieved mainly using mechanical fluctuation and thermal effects. Mechanical fluctuation can promote water droplets in crude oil to gather together so that they move downwards in the direction of gravity. Furthermore, mechanical fluctuation can also improve the solubility of natural emulsifiers in crude oil, such as paraffin, pectin, and asphalt, so that the mechanical strength of the oil-water interfacial film can be decreased. The decrease of the mechanical strength of the oil-water interfacial film is conducive to oil-water settling separation.

Thermal effects produced by ultrasound can decrease the mechanical strength of the oil-water interfacial film and the viscosity of crude oil. On the one hand, the increase of temperature at the oil-water interface is conducive to breaking the oil-water interfacial film; on the other hand, thermal energy converted from part of the sound energy absorbed by crude oil can reduce the viscosity of crude oil, which is conducive to water droplets moving downwards in the direction of gravity.

But why does the combined method of ultrasound and chemical demulsifier have the best demulsification effect? That is because ultrasound can promote water droplets in crude oil to gather together; chemical demulsifier can greatly decrease the surface tension of water droplets so that the mechanical strength of the oil-water interfacial film can be degraded. Due to the mechanical strength decrease of oilwater interfacial film, big water droplets merge into larger ones, and then they will move downwards in the direction of gravity.

\section{The Impact of Ultrasonic Parameters on Crude Oil Demulsification Using the Combined Method of Ultrasound and Chemical Demulsifier}

4.1. The Impact of Ultrasonic Power on Crude Oil Demulsification Using the Combined Method of Ultrasound and Chemical Demulsifier. This experiment is carried out under constant temperature, constant chemical demulsifier concentration, 


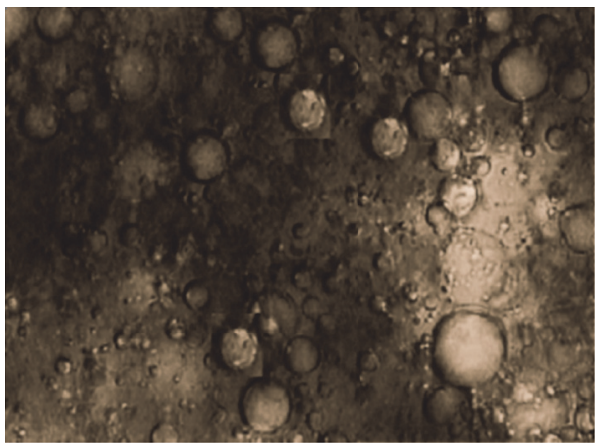

(a)

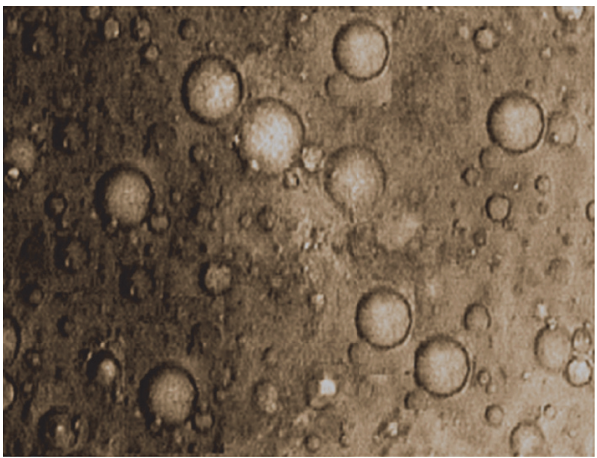

(c)

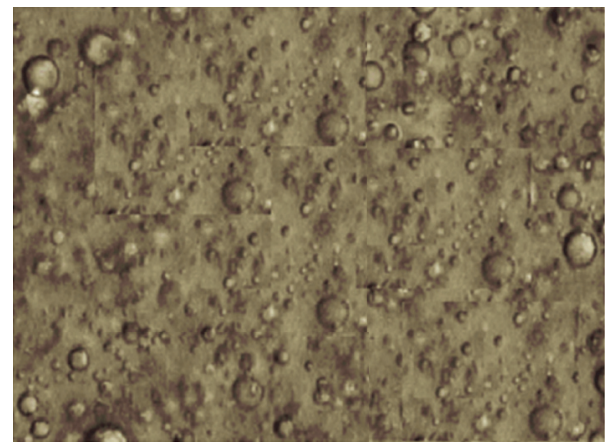

(b)

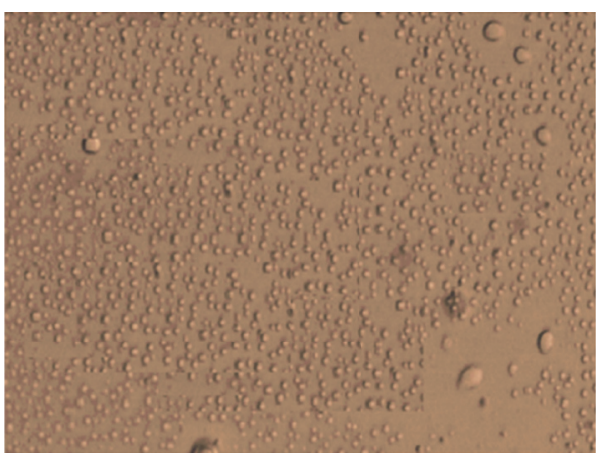

(d)

FIGURE 8: The effect of crude oil demulsification using different methods. (a) Before demulsification; (b) the effect of crude oil demulsification using chemical demulsifier; (c) the effect of crude oil demulsification using ultrasonic treatment; (d) the effect of crude oil demulsification using the combined method of ultrasound and chemical demulsifier.

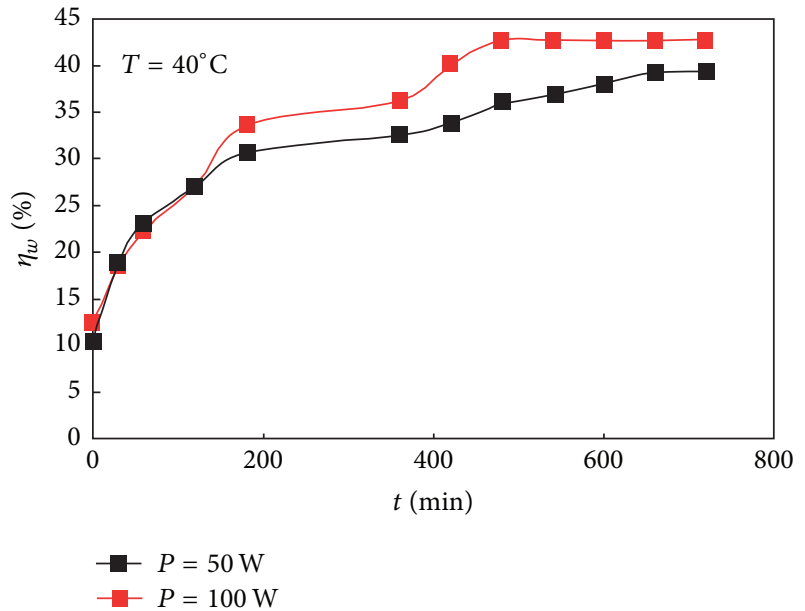

FIGURE 9: The impact of ultrasonic powers $(50 \mathrm{~W}$ and $100 \mathrm{~W})$ on sonochemistry dehydration.

and constant ultrasonic treatment time. The impact of ultrasonic power on sonochemistry dehydration is shown in Figures 9 and 10.

As can be seen in Figures 9 and 10, the final dehydration rate by using the combined method of ultrasound and chemical demulsifier increases with the increase of ultrasonic power. That is because ultrasound with higher power can

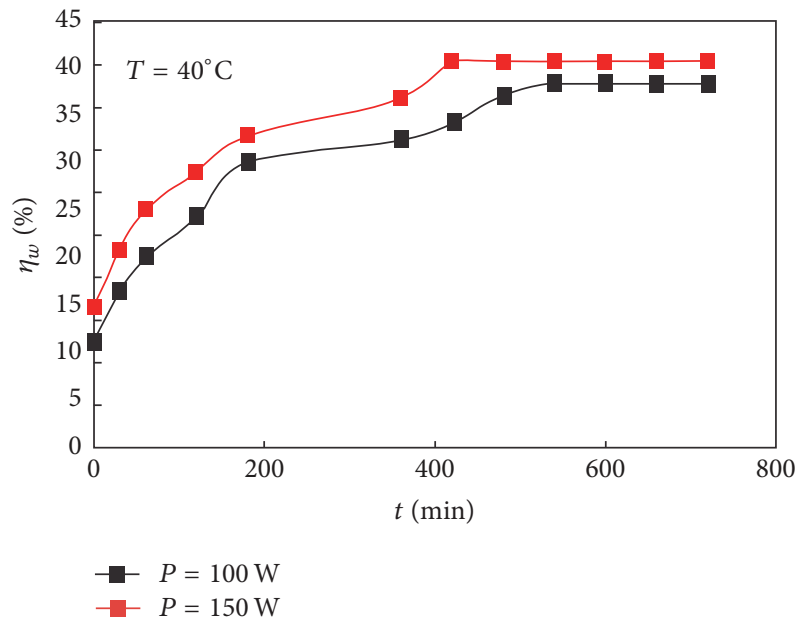

FIGURE 10: The impact of ultrasonic power $(100 \mathrm{~W}$ and $150 \mathrm{~W})$ on sonochemistry dehydration.

cause more intensive mechanical vibrations so that the effect of ultrasonic dehydration can be improved significantly.

4.2. The Impact of Ultrasonic Treatment Time on Crude Oil Demulsification Using the Combined Method of Ultrasound and Chemical Demulsifier. This experiment is carried out under constant temperature, constant chemical demulsifier 


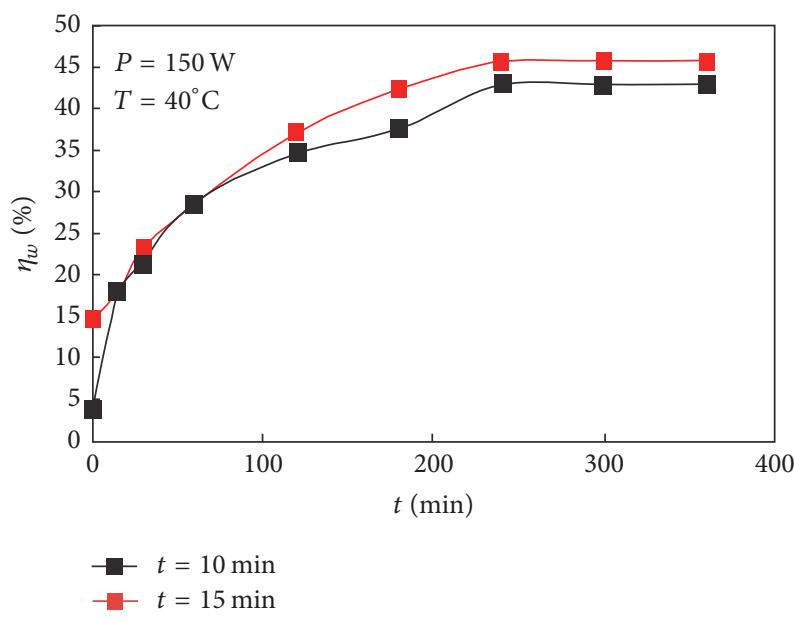

FIGURE 11: The impact of different ultrasonic treatment time (10 min and $15 \mathrm{~min}$ ) on sonochemistry dehydration.

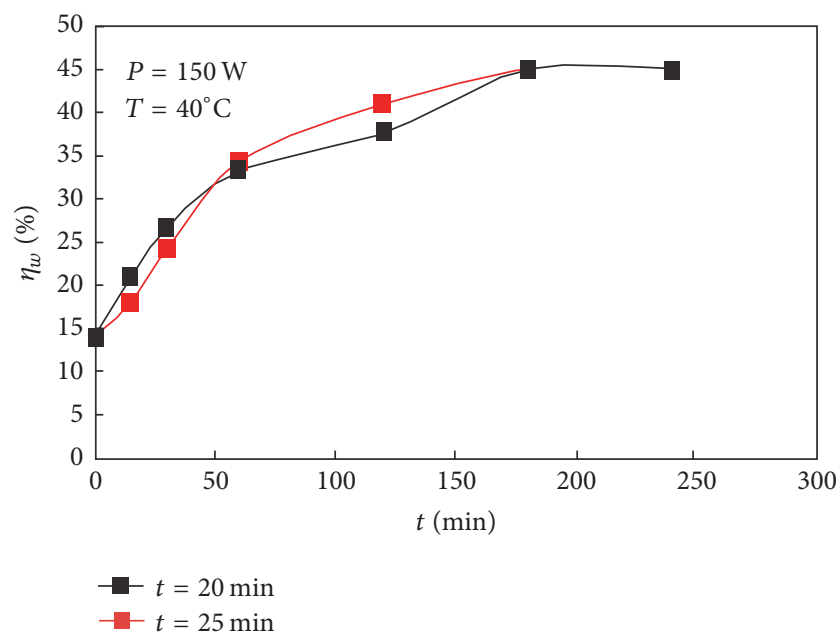

FIGURE 12: The impact of different ultrasonic treatment time (20 min and $25 \mathrm{~min}$ ) on sonochemistry dehydration.

concentration, and constant ultrasonic power. The impact of ultrasonic treatment time on sonochemistry dehydration is shown in Figures 11 and 12.

As can be seen in Figures 11 and 12, this important conclusion indicates that there is no need to spend more time to dehydrate watery crude oil using the combined method of ultrasound and chemical demulsifier.

\section{Conclusion}

The novelty of this manuscript is that the comparison of crude oil demulsification using ultrasonic treatment, chemical agent alone, and the combination of ultrasonic and chemical demulsification methods, respectively, was investigated. Results prove that the combined method of ultrasound and chemical demulsifier has the best demulsification effect, followed by chemical demulsifier and ultrasonic treatment. Experiments also indicate that the combined method of ultrasound and chemical demulsifier not only can achieve the purpose of heavy crude oil demulsification-dehydration but also can shorten demulsification -dehydration time. Furthermore, it is proven that the final dehydration rate by using the combined method of ultrasound and chemical demulsifier increases with the increase of ultrasonic power and temperature and is almost not changed with the increase of ultrasonic treatment time. These conclusions provide important reference for on-site application of sonochemistry dehydration technique.

\section{Conflicts of Interest}

The authors declare that they have no conflicts of interest.

\section{References}

[1] J. Wu, Y. Xu, T. Dabros, and H. Hamza, "Effect of demulsifier properties on destabilization of water-in-oil emulsion," Energy and Fuels, vol. 17, no. 6, pp. 1554-1559, 2003.

[2] H. Ming, High-Temperature Heavy Oil Dehydration Static Experimental Study of Ultrasonic Demulsificatian, Daqing Petroleum Institute, 2010.

[3] G. R. Check, "Two-stage ultrasonic irradiation for dehydration and desalting of crude oil: a novel method," Chemical Engineering and Processing: Process Intensification, vol. 81, pp. 72-78, 2014.

[4] W. Xie, R. Li, and X. Lu, "Pulsed ultrasound assisted dehydration of waste oil," Ultrasonics Sonochemistry, vol. 26, pp. 136-141, 2015.

[5] L. J. Stack, P. A. Carney, H. B. Malone, and T. K. Wessels, "Factors influencing the ultrasonic separation of oil-in-water emulsions," Ultrasonics Sonochemistry, vol. 12, no. 3, pp. 153160, 2005.

[6] G. D. Pangu and D. L. Feke, "Acoustically aided separation of oil droplets from aqueous emulsions," Chemical Engineering Science, vol. 59, no. 15, pp. 3183-3193, 2004.

[7] J. Jiao, Y. He, T. Leong et al., "Experimental and theoretical studies on the movements of two bubbles in an acoustic standing wave field," Journal of Physical Chemistry B, vol. 117, no. 41, pp. 12549-12555, 2013.

[8] C. Browne, R. F. Tabor, D. Y. C. Chan, R. R. Dagastine, M. Ashokkumar, and F. Grieser, "Bubble coalescence during acoustic cavitation in aqueous electrolyte solutions," Langmuir, vol. 27, no. 19, pp. 12025-12032, 2011.

[9] W. Xie, R. Li, X. Lu, P. Han, and S. Gu, "Acoustically aided coalescence of water droplets and dehydration of crude oil emulsion," Korean Journal of Chemical Engineering, vol. 32, no. 4, pp. 643-649, 2015.

[10] G. R. Check and D. Mowla, "Theoretical and experimental investigation of desalting and dehydration of crude oil by assistance of ultrasonic irradiation," Ultrasonics Sonochemistry, vol. 20, no. 1, pp. 378-385, 2013.

[11] S. Nii, S. Kikumoto, and H. Tokuyama, "Quantitative approach to ultrasonic emulsion separation," Ultrasonics Sonochemistry, vol. 16, no. 1, pp. 145-149, 2009.

[12] F. J. Trujillo, P. Juliano, G. Barbosa-Cánovas, and K. Knoerzer, "Separation of suspensions and emulsions via ultrasonic standing waves-a review," Ultrasonics Sonochemistry, vol. 21, no. 6, pp. 2151-2164, 2014. 
[13] G. Ye, X. Lü, F. Peng, P. Han, and X. Shen, "Pretreatment of crude oil by ultrasonic-electric united desalting and dewatering," Chinese Journal of Chemical Engineering, vol. 16, no. 4, pp. 564-569, 2008.

[14] M. Mohsin and M. Meribout, "Oil-water de-emulsification using ultrasonic technology," Ultrasonics Sonochemistry, vol. 22, pp. 573-579, 2015.

[15] S. Gou, J. Da, Y. Zhang, P. Hang, and J. Zhang, "A method and apparatus for demulsifying an oil-water emulsion via ultrasonic effect," Patent no. WO/2005/030360, 2005.

[16] J. Y. Yu, P. Yuan, and L. Yu, "Experiment study on the sound-field parameters for crude-oil dehydration by ultrasonic demulsification," Applied Acoustics, vol. 20, no. 3, pp. 27-30, 2001 (Chinese).

[17] N. Aboobaker, D. Blackmore, and J. Meegoda, "Mathematical modeling of the movement of suspended particles subjected to acoustic and flow fields," Applied Mathematical Modelling, vol. 29, no. 6, pp. 515-532, 2005.

[18] G. D. Pangu, Acoustically aided coalescence of droplets in aqueous emulsions [Ph.D. thesis], Case Western Reserve University, Cleveland, Ohio, USA, 2006.

[19] M. Postema, P. Marmottant, C. T. Lancée, S. Hilgenfeldt, and N. D. Jong, "Ultrasound-induced microbubble coalescence," Ultrasound in Medicine and Biology, vol. 30, no. 10, pp. 13371344, 2004.

[20] X. Xi, F. B. Cegla, M. Lowe et al., "Study on the bubble transport mechanism in an acoustic standing wave field," Ultrasonics, vol. 51, no. 8, pp. 1014-1025, 2011.

[21] L. Hongwei, "High show in the army. Guo Limei. Ground engineering model of crude oil dehydration method," Oil and Gas Field, vol. 26, no. 3, pp. 32-33, 2007.

[22] H. Tongliang and Y. K. M. Liangjun, "Progress in research of crude oil dewatering and desalting," Journal of Fushun Petroleum Institute, vol. 23, no. 3, pp. 1-5, 2003.

[23] T. J. Mason, A. J. Cobley, J. E. Graves, and D. Morgan, "New evidence for the inverse dependence of mechanical and chemical effects on the frequency of ultrasound," Ultrasonics Sonochemistry, vol. 18, no. 1, pp. 226-230, 2011.

[24] J. S. Eow and M. Ghadiri, "Electrostatic enhancement of coalescence of water droplets in oil: a review of the technology," Chemical Engineering Journal, vol. 85, no. 2-3, pp. 357-368, 2002.

[25] Z.-S. Bai and H.-L. Wang, "Crude oil desalting using hydrocyclones," Chemical Engineering Research and Design, vol. 85, no. 12, pp. 1586-1590, 2007.

[26] R. Zolfaghari, A. Fakhru'l-Razi, L. C. Abdullah, S. S. E. H. Elnashaie, and A. Pendashteh, "Demulsification techniques of water-in-oil and oil-in-water emulsions in petroleum industry," Separation and Purification Technology, vol. 170, pp. 377-407, 2016.

[27] X. Zhang, Experimental studies on demulsification of produced liquid containing heavy oil by sonochemical treatment [M.S. thesis], School of Petroleum Engineering, China University of Petroleum (East China), 2008. 

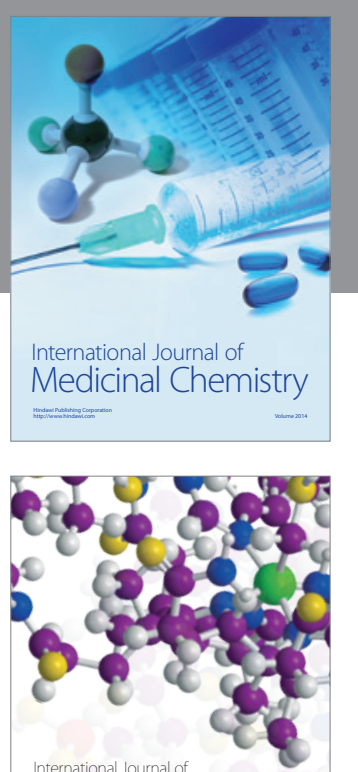

Carbohydrate Chemistry

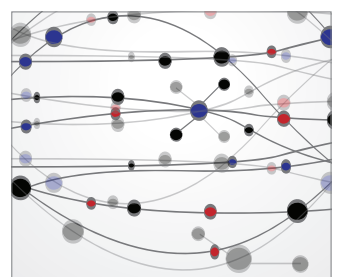

The Scientific World Journal
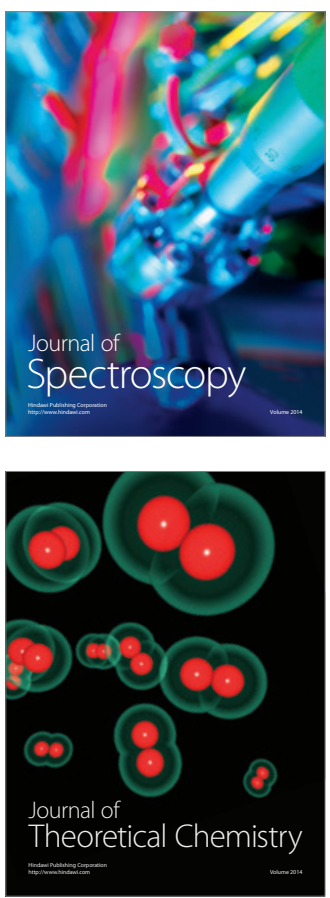
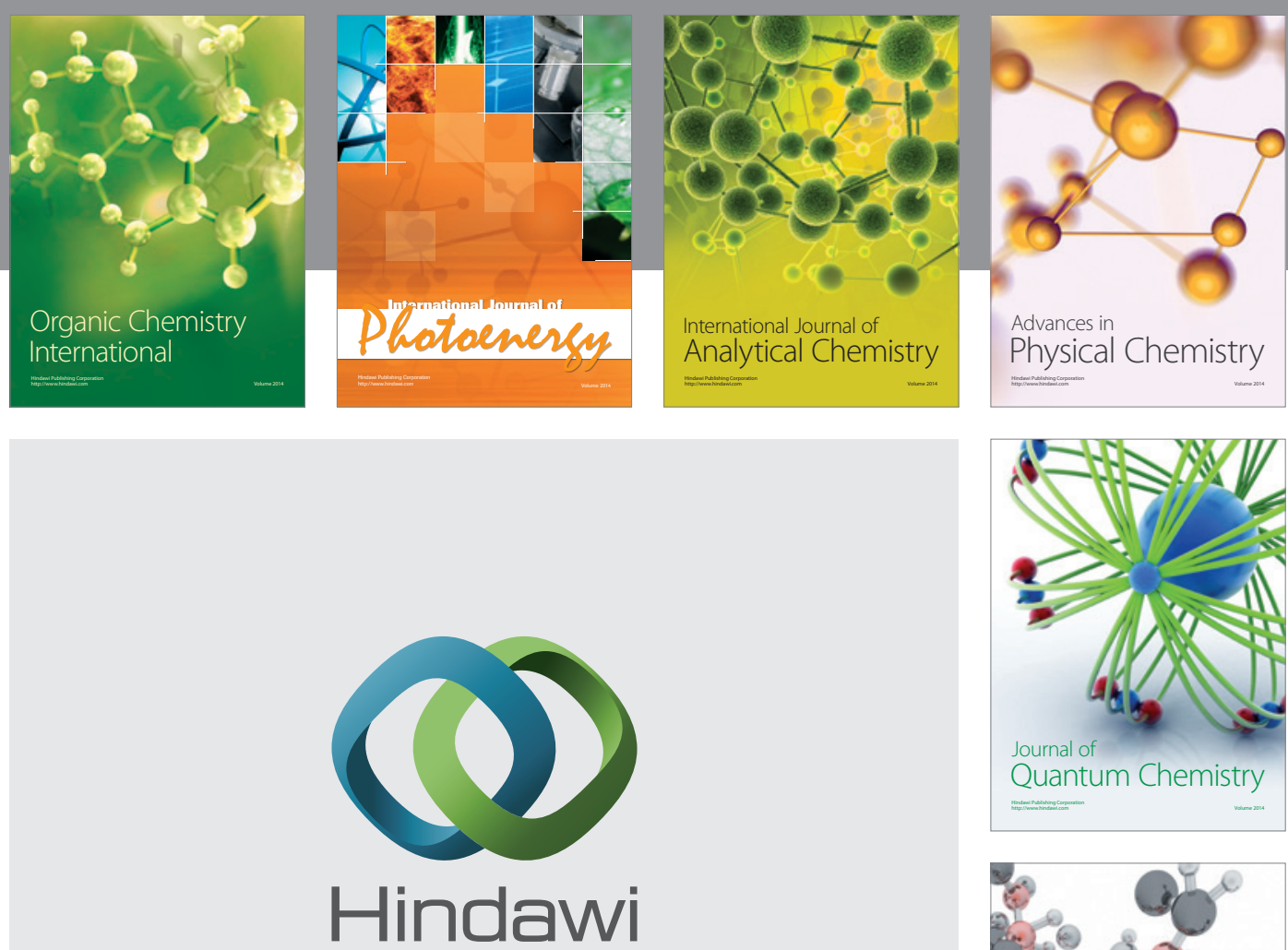

Submit your manuscripts at

https://www.hindawi.com

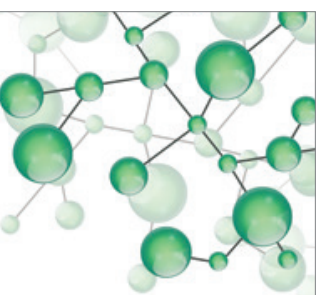

International Journal of

Inorganic Chemistry
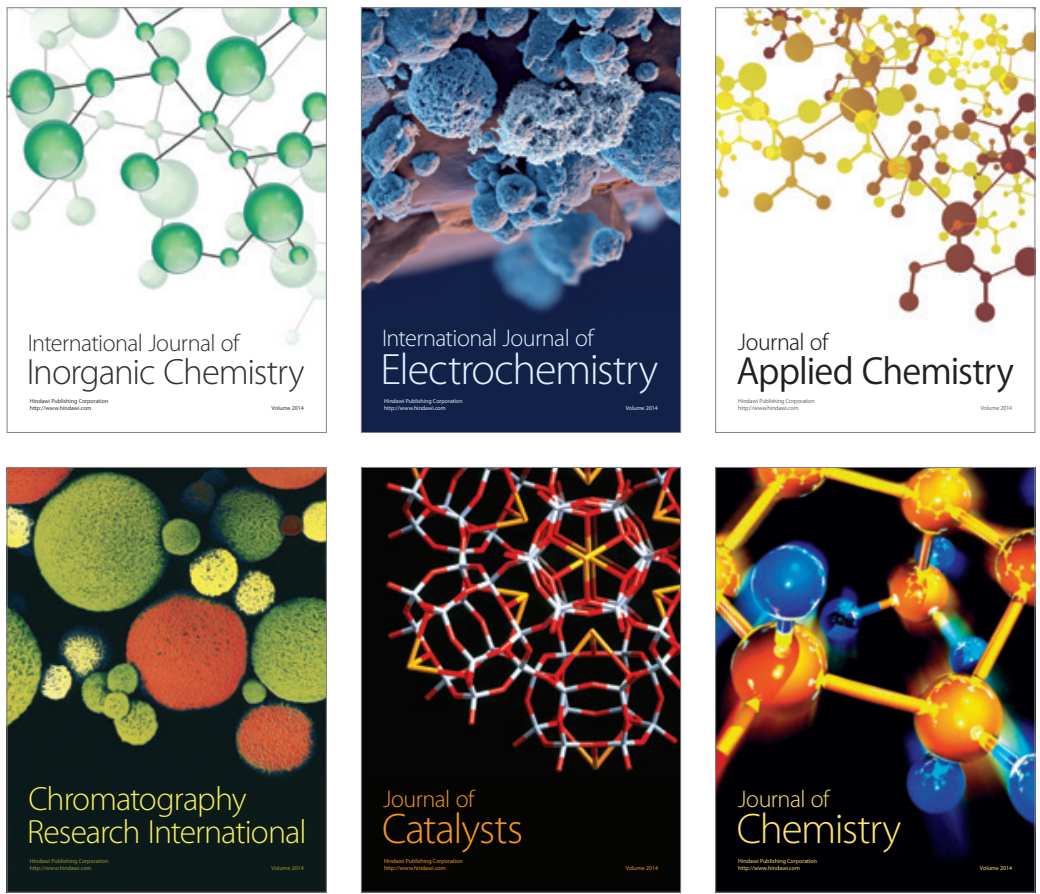

Journal of

Applied Chemistry
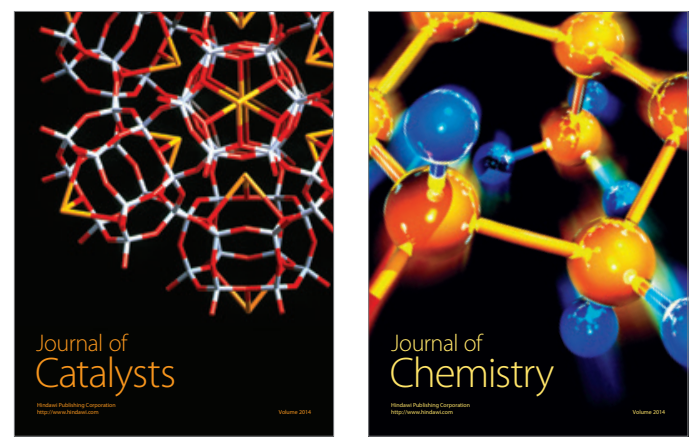
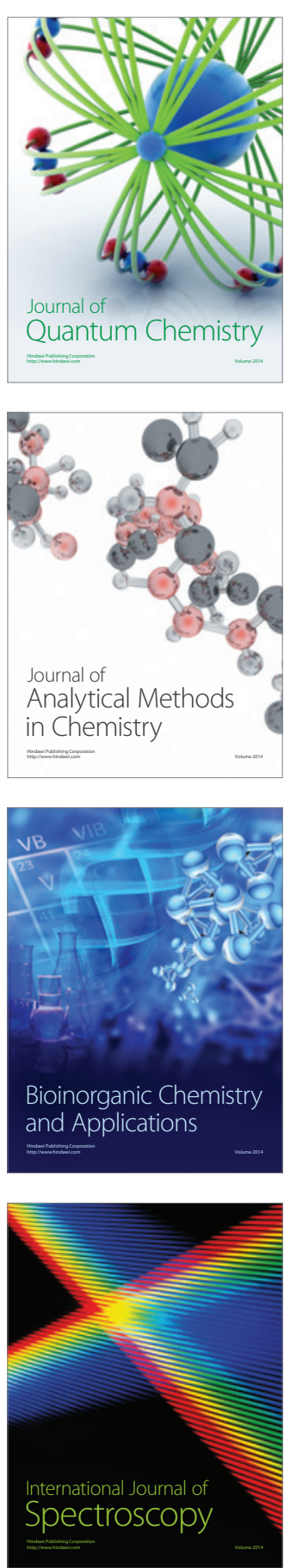